\title{
Chalmers' choice: make cuts or go under
}

Few museums have witnessed as profound a transformation in recent years as the Natural History Museum in London has under the directorship of Neil Chalmers. museum was struggling to make ends meet and almost totally dependent on dwindling public funds, all but two per cent of which were eaten up by salaries. But in the last

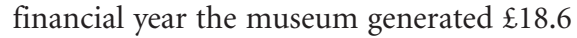
million (US\$31 million) of its $\mathfrak{£} 46.3$ million turnover itself-just over 40 per cent.

Chalmers' actions have been controversial. They involved shedding or redeploying about 50 of the 290 scientific, curatorial and technical support posts, and refocusing research on fewer areas, putting some collections on a 'care-and-maintenance' footing (see Nature 344, 805; 1990).

Many experts in fields considered to be outside the museum's core interests have taken early retirement. Ten years on, there are now 270 staff funded by the museum, with a further 55 postdoctoral fellows and other staff paid by external agencies.

The link between museum research and the health of taxonomy and systematics as a discipline is a strong one. When the museum announced the job cuts in 1990, the then president of the Royal Society, Sir George Porter, received more than 800 letters, "all expressing concern that the great collections of the Natural History Museum and the research associated with them were in danger of neglect or
When he took up the post in 1988, the

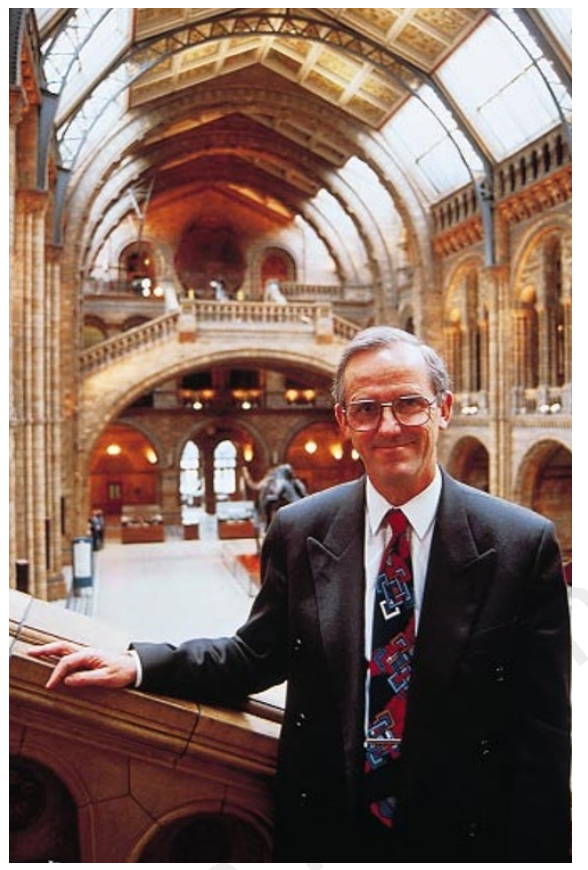

Chalmers: the results of museum research must be made public more speedily and effectively.

extinction through lack of support".

As a result, the House of Lords Committee on Science and Technology set up an inquiry into the state of systematic biology in the United Kingdom. Their recommendations, published in January 1992, included a modest increase in funding $-\mathfrak{E} 5$ million

keep costs down, focusing only on the most endangered or ecologically important groups. Given the sheer size of the world's collections, "you are talking millions, even if you only spend a few dollars per beetle," points out Stephan Michalowski, executive secretary of the OECD Megascience Forum.

Co-ordinating existing digitalization programmes is also a goal of the

Consortium of European Taxonomic Facilities, a grouping of the major European museums. Similarly, an informal consortium of a dozen leading US museums is discussing co-ordinating their systematics work, including digitalization.

"We've made some progress, but it hasn't been enough," says Michael Novacek, provost of the American Museum of Natural History in New York. "Museums have had difficulty joining together to work on things because a lot of them have had to contend with challenges at home," he adds.

Discussions are also under way to integrate a UK-led programme, Species 2000 , as the core of the early phases of GBIF. Species 2000 was launched in 1994 by the
International Union of Biological Sciences, in co-operation with the Committee on Data for Science and Technology and the International Union of Microbiological Societies.

The initiative has set its sights lower than GBIF, and would focus on bringing together databases of only existing described species to form a shared resource, while stopping short of digitalizing the specimens. Work is already under way to enter 40 per cent of the world's described species. Much of the information is coming from major museums, particularly in Europe.

Frank Bisby, professor of botany at the University of Reading in the United Kingdom and the chairman of the project, says that "pragmatism and quality" are its key criteria.

"Why haven't the taxonomists done this before?" asks Bisby. "At the moment there is gross inefficiency, with information distributed throughout countries and "desktop delivery of the world's existing knowledge on biodiversity". institutions." What we are planning is over five years - for systematics and taxonomy (see Nature 355, 488; 1992).

By a fortuitous coincidence, the debate on the committee's report in the House of Lords came soon after the United Nations Earth Summit in Rio de Janeiro. At the summit meeting, the then Prime Minister, John Major, announced the Darwin Initiative, to provide modest sums $-\mathfrak{E} 6$ million to date - for systematics. Under the initiative, staff from museums and botanic gardens train taxonomists from developing countries.

Much of the resistance of researchers to the changes at the museum stemmed from opposition to the disbanding of teams of collections-based researchers on certain groups of species. The cuts have undoubtedly resulted in the irretrievable loss of a wealth of expertise which will have repercussions on the museum's activities for decades.

The cuts have been compensated for to some extent by the recruitment of around 100 university-style postdoctoral researchers financed by external agencies, such as the Natural Environment Research Council.

Two positive outcomes of the influx of outside scientists have been heightened external awareness of the museum's activities, and a greater 'footprint' in peerreviewed journals, according to the director of science, Paul Henderson.

A further boost to researcher mobility has come from the recent award of a ECU680,000 (US\$750,000) grant from the European Union's Framework research programme to fund researchers from other European countries to visit the museum for up to three months at a time.

But financial austerity has forced the museum to abandon its scheme for funding undergraduates to spend the summer doing curatorial work, closing an avenue that in the past opened up careers for many scientists.

Chalmers defends his tough actions on the grounds that the urgency of the situation made drastic action necessary and that otherwise "we would have gone into a long and painful decline". Exhibitions would have been lacklustre, he argues, staff would have left and not been replaced, while the science would have become fragmented and unsupported, with no focus or plan.

According to Chalmers, a crucial challenge to museums in meeting real world needs will be to make collections-based research and information available in a form and at a speed — "unfamiliar to many who work in museums" - that makes them accessible to a wide range of users.

Chalmers argues that this requires researchers to communicate data "in brief and rapid reports," rather than in scholarly monographs, while taking full advantage of networked databases. 